\title{
Short communication: Association of an OLR1 polymorphism with milk production traits in the Israeli Holstein population
}

\author{
X. Wang, ${ }^{*}$ F. Peñagaricano, $†$ R. Tal-Stein, $\ddagger$ E. Lipkin, $\ddagger$ and H. Khatib $\dagger^{1}$ \\ ${ }^{*}$ College of Animal Science and Technology, Northwest A\&F University, Yangling, Shaanxi, 712100, P. R. China \\ †Department of Animal Sciences, University of Wisconsin, Madison 53706 \\ $\ddagger$ Department of Genetics, The Hebrew University of Jerusalem, 91904 Jerusalem, Israel
}

\begin{abstract}
Previous studies have reported significant associations between haplotypes of the oxidized low-density lipoprotein (lectin-like) receptor 1 (OLR1) gene and a single nucleotide polymorphism (SNP) in its $3^{\prime}$-untranslated region with milk composition and health traits in different cattle populations. However, to provide a better estimation of the impact and size of the association of OLR1 with production traits, a need exists to validate its genomic association in additional cattle populations. Thus, the objective of this study was to perform association analysis of the OLR1 SNP with milk traits in the Israeli Holstein population. Estimated breeding values of milk composition traits and somatic cell score were obtained for a total of 1,211 Holstein cows, which were genotyped for a SNP in the 3'-untranslated region. Statistical analysis revealed significant association between the OLR1 SNP and protein percentage and somatic cell score. Thus, the validation of association of this SNP with milk traits in independent cattle populations suggests $O L R 1$ as a candidate gene for further functional studies.
\end{abstract}

Key words: oxidized low-density lipoprotein (lectinlike) receptor 1 gene, single nucleotide polymorphism, association, Holstein

\section{Short Communication}

The oxidized low-density lipoprotein (lectin-like) receptor 1 ( $\boldsymbol{O L R} \mathbf{1})$ plays an important role in the degradation of oxidized low-density lipoprotein, which can cause damage to the arterial endothelium (Imanishi et al., 2002). In cattle, several QTL affecting milk production traits have been reported in the vicinity of $O L R 1$, including milk fat percentage (Heyen et al., 1999), milk fat yield (Olsen et al., 2002), and milk yield (de Koning et al., 2001). In recent studies, SNP in the OLR1

Received October 2, 2011.

Accepted November 11, 2011.

${ }^{1}$ Corresponding author: hkhatib@wisc.edu gene were found to be associated with milk production and health traits in cattle. For example, Khatib et al. (2006) reported significant associations of a SNP in the $3^{\prime}$-untranslated region (UTR) region and haplotypes of OLR1 with milk fat yield and fat percentage in a granddaughter-design Holstein bull population. Association between $O L R 1$ haplotypes and milk production traits was further confirmed in a daughter-design study of Holstein cows and in an Italian Brown Swiss population (Khatib et al., 2007). Also, Schennink et al. (2009) reported a significant association between $O L R 1$ and milk fat percentage in Dutch Holstein-Friesian cattle.

Although other SNP were identified in OLR1, only the 3 '-UTR SNP was found to be associated with milk traits in the Holstein population (Khatib et al., 2006). Interestingly, quantitative real-time PCR analysis revealed that the expression level of $O L R 1$ was higher in individuals bearing the $\mathrm{CC}$ genotype compared with the AA genotype of the $3^{\prime}$-UTR SNP, suggesting that C is the nucleotide causing increased expression of $O L R 1$ or is in strong linkage disequilibrium with the causative SNP (Khatib et al., 2006). To elucidate the possible functions of this SNP in milk composition, a need exists to validate its genomic association in additional cattle populations. Therefore, the objective of this study was to analyze the association between the 3 '-UTR SNP and milk production and health traits in the Israeli Holstein population.

Estimated breeding values of milk yield, milk fat and protein yields, milk fat and protein percentages, and SCS, along with milk samples, were obtained for a total of 1,211 Holstein cows from the Israeli Cattle Breeders' Association (Industrial Park, Caesarea, Israel). Table 1 shows the summary statistics of EBV for the analyzed traits. Genomic DNA was extracted from milk samples using the GFX Genomic Blood DNA Purification kit (Amersham Biosciences, Piscataway, NJ). Single nucleotide polymorphism A/C (known as SNP8232 in previous studies) in the 3 '-UTR region at position 10497 of OLR1 (chromosome 5; GenBank accession no. NC_007303.4; 107080852..107092157) was genotyped as described in Khatib et al. $(2006,2007)$. 
Table 1. Summary statistics of estimated breeding values for milk traits

\begin{tabular}{lccc}
\hline Trait & Mean & SD & $\begin{array}{c}\text { Range } \\
\text { (minimum, maximum) }\end{array}$ \\
\hline Milk yield $(\mathrm{kg})$ & 80 & 171 & $-375,820$ \\
Protein yield $(\mathrm{kg})$ & 4.88 & 4.13 & $-11.15,19.70$ \\
Protein percentage $(\%)$ & 0.023 & 0.029 & $-0.094,0.093$ \\
Fat yield $(\mathrm{kg})$ & 6.41 & 6.69 & $-18.45,30.70$ \\
Fat percentage (\%) & 0.036 & 0.067 & $-0.172,0.258$ \\
SCS & -0.110 & 0.134 & $-0.469,0.360$ \\
\hline
\end{tabular}

Association between SNP10497 and each trait was analyzed using the following mixed linear model:

$$
y_{i j}=\mu+\beta S N P_{i}+\text { animal }_{j}+e_{i j}
$$

where $y_{i j}$ represents the EBV of animal $j$ for the trait under consideration, $\mu$ is the general mean, $S N P_{i}$ is the number of copies of 1 allele of the SNP (corresponding to 0,1 , or 2 copies) carried by the $j$ th animal, $\beta$ is the regression coefficient for the SNP considered (also known as the allele substitution effect), animal repre- $_{j}$ sents the random additive genetic effect of the $j$ th animal $(j=1,2, \ldots 1,211)$, and $e_{i j}$ represents the random residual for each observation. The distributions of animal $_{j}$ and $e_{i j}$ were assumed as $N\left(0, \mathbf{A} \sigma_{a}^{2}\right)$ and $N\left(0, \mathbf{I} \sigma_{e}^{2}\right)$, respectively, where $\mathbf{A}$ represents the matrix of additive relationships $(4,868 \times 4,868)$ between animals in the pedigree. Association between the SNP and each trait was tested using a likelihood ratio test compared with a reduced model without the SNP effect. All analyses were performed using the pedigreemm package (Vazquez et al., 2010) of the R language/environment (R Development Core Team, 2009).

The $\mathrm{C}$ allele frequency was 0.58 in the Israeli population compared with 0.54 in the US cow population (Khatib et al., 2006). The genotypic frequencies were $0.13,0.58$, and 0.29 for the AA, AC, and CC genotypes, respectively. The Hardy-Weinberg test revealed that this SNP is not in equilibrium in the Israeli Holstein population. Analysis of SNP10497 revealed significant associations with protein percentage $(P=0.018)$ and SCS $(P=0.011$; Table 2$)$. Allele $\mathrm{C}$ produces an incremental increase in SCS with an allele substitution effect of $0.015 \pm 0.006$ points and also an incremental increase in protein percentage with an allele substitution effect of $0.003 \pm 0.001$. Thus, the SNP10497 may be neutral for selection purposes by having a positive effect on protein percentage - which is desirable - and by having a positive effect on SCS, which is undesirable. This contradiction may contribute to maintaining the polymorphism in the population.

Thus, the results obtained in this study provide additional confirmation of previous reports of the as- sociation of $O L R 1$ with milk composition traits and SCS. A moderate association between $O L R 1$ and SCS $(P=0.05)$ was also reported in the Italian Brown Swiss population (Khatib et al., 2007). As a receptor, OLR1 is directly involved in internalization into the cell and degradation of the oxidized low-density lipoprotein, which in turn, affects fat metabolism. The mechanisms by which SNP10497 can affect the levels of protein or SCS in milk are not known. However, the validation of the association between this SNP in independent cattle breeds and populations from different countries (United States, the Netherlands, Italy, and Israel) and by different experimental designs (e.g., daughter- and granddaughter-design) suggest $O L R 1$ as a candidate gene for further functional analysis.

Strong evidence exists that the 3 '-UTR sequences are involved in the regulation of gene expression through different mechanisms including binding of transcription factors, RNA stability, polyadenylation, and gene silencing, among others (Conne et al., 2000; Chen et al., 2003). Given that the significant SNP is located in the $3^{\prime}$-UTR of OLR 1 and that genotypes of this SNP were associated with expression levels of the gene (Khatib et al., 2006), these findings provide additional support to the proposition of $O L R 1$ as a candidate gene for further study to elucidate the mechanisms by which it affects milk composition and health traits.

\section{ACKNOWLEDGMENTS}

This research was supported by The Draper Technology Innovation Fund from University of WisconsinMadison Graduate School and by USDA Hatch grant

Table 2. Results of the association analysis between SNP10497 and milk production traits and SCS

\begin{tabular}{lc}
\hline Trait & $P$-value \\
\hline Milk yield $(\mathrm{kg})$ & 0.853 \\
Protein yield (kg) & 0.165 \\
Protein percentage (\%) & 0.018 \\
Fat yield (kg) & 0.434 \\
Fat percentage (\%) & 0.236 \\
SCS & 0.011 \\
\hline
\end{tabular}


no. WIS04895 from the University of Wisconsin-Madison. X. Wang was supported by the China Scholarship Council (Beijing, P. R. China). The authors thank the Israeli Cattle Breeders' Association (Industrial Park, Caesarea, Israel) for providing milk samples and phenotypic data. The authors thank Morris Soller (The Hebrew University of Jerusalem, Israel) for assistance in accessing the data, and reviewing a draft of the manuscript.

\section{REFERENCES}

Chen, Q., S. E. Reis, C. Kammerer, W. Y. Craig, S. E. LaPierre, E. L. Zimmer, D. M. McNamara, D. F. Pauly, B. Sharaf, R. Holubkov, C. N. Bairey Merz, G. Sopko, F. Bontempo, and M. I. Kamboh. 2003. Genetic variation in lectin-like oxidized low-density lipoprotein receptor 1 (LOX1) gene and the risk of coronary artery disease. Circulation 107:3146-3151.

Conne, B., A. Stutz, and J.-D. Vassalli. 2000. The 3' untranslated region of messenger RNA: A molecular 'hotspot' for pathology? Nat. Med. 6:637-641.

de Koning, D. J., N. F. Schulman, K. Elo, S. Moisio, R. Kinos, J. Vilkki, and A. Mäki-Tanila. 2001. Mapping of multiple quantitative trait loci by simple regression in half-sib designs. J. Anim. Sci. 79:616-622.

Heyen, D. W., J. I. Weller, M. Ron, M. Band, J. E. Beever, E. Feldmesser, Y. Da, G. R. Wiggans, P. M. VanRaden, and H. A. Lewin.
1999. A genome scan for QTL influencing milk production and health traits in dairy cattle. Physiol. Genomics 1:165-175.

Imanishi, T., T. Hano, T. Sawamura, S. Takarada, and I. Nishio. 2002. Oxidized low density lipoprotein potentiation of Fas-induced apoptosis through lectin-like oxidized-low density lipoprotein receptor-1 in human umbilical vascular endothelial cells. Circ. J. 66:1060-1064.

Khatib, H., S. D. Leonard, V. Schutzkus, W. Luo, and Y. M. Chang. 2006. Association of the OLR1 gene with milk composition in Holstein dairy cattle. J. Dairy Sci. 89:1753-1760.

Khatib, H., G. J. Rosa, K. Weigel, F. Schiavini, E. Santus, and A. Bagnato. 2007. Additional support for an association between OLR1 and milk fat traits in cattle. Anim. Genet. 38:308-310.

Olsen, H. G., L. Gomez-Raya, D. I. Våge, I. Olsaker, H. Klungland, M. Svendsen, T. Ådnøy, A. Sabry, G. Klemetsdal, N. Schulman, W. Krämer, G. Thaller, K. Rønningen, and S. Lien. 2002. A genome scan for quantitative trait loci affecting milk production in Norwegian dairy cattle. J. Dairy Sci. 85:3124-3130.

R Development Core Team. 2009. R: A Language and Environment for Statistical Computing. R Foundation for Statistical Computing, Vienna, Austria.

Schennink, A., H. Bovenhuis, K. M. Léon-Kloosterziel, J. A. van Arendonk, and M. H. P. W. Visker. 2009. Effect of polymorphisms in the FASN, OLR1, PPARGC1A, PRL and STAT5A genes on bovine milk-fat composition. Anim. Genet. 40:909-916.

Vazquez, A. I., D. M. Bates, G. J. M. Rosa, D. Gianola, and K. A. Weigel. 2010. Technical note: An R package for fitting generalized linear mixed models in animal breeding. J. Anim. Sci. 88:497-504. 